University of Nebraska - Lincoln

DigitalCommons@University of Nebraska - Lincoln

2019

DNMT3a in the hippocampal CA1 is crucial in the acquisition of morphine self-administration in rats

Jian-Jun Zhang

Feng-Ze Jiang

Wei Zheng

Ying Duan

Su-Bo Jin

See next page for additional authors

Follow this and additional works at: https://digitalcommons.unl.edu/psychfacpub

Part of the Medicine and Health Sciences Commons, and the Psychology Commons

This Article is brought to you for free and open access by the Psychology, Department of at

DigitalCommons@University of Nebraska - Lincoln. It has been accepted for inclusion in Faculty Publications, Department of Psychology by an authorized administrator of DigitalCommons@University of Nebraska - Lincoln. 


\section{Authors}

Jian-Jun Zhang, Feng-Ze Jiang, Wei Zheng, Ying Duan, Su-Bo Jin, Fang Shen, Jing Liang, Ming Li, and Nan Sui 


\title{
DNMT3a in the hippocampal CA1 is crucial in the acquisition of morphine self-administration in rats
}

\author{
Jian-Jun Zhang, ${ }^{1,2}$ Feng-Ze Jiang, ${ }^{1,2}$ Wei Zheng, ${ }^{1,2}$ \\ Ying Duan, ${ }^{1,2}$ Shu-Bo Jin, ${ }^{1,2}$ Fang Shen, ${ }^{1,2}$ \\ Jing Liang, ${ }^{1,2}$ Ming Li, ${ }^{3}$ and Nan Sui ${ }^{1,2}$
}

1 CAS Key Laboratory of Mental Health, Institute of Psychology, Beijing, China

2 Department of Psychology, University of Chinese Academy of Sciences, Beijing, China

3 Department of Psychology, University of Nebraska-Lincoln, Lincoln, Nebraska, USA

Jian-Jun Zhang and Feng-Ze Jiang contributed equally to this work.

Corresponding author — Nan Sui, Key Laboratory of Mental Health, Institute of Psychology, Chinese Academy of Sciences, 16 Lincui Rd, Beijing, 100101, China. Email: suin@psych.ac.cn

ORCID Jian-Jun Zhang https://orcid.org/0000-0001-7526-7234

\begin{abstract}
Drug-reinforced excessive operant responding is one fundamental feature of longlasting addiction-like behaviors and relapse in animals. However, the transcriptional regulatory mechanisms responsible for the persistent drug-specific (not natural rewards) operant behavior are not entirely clear. In this study, we demonstrate a key
\end{abstract}

Citation: Zhang, J.J., Jiang, F.Z., Zheng, W., Duan, Y., Jin, S.B., Shen, F., Liang, J., Li, M., Sui, N. (2019). DNMT3a in the hippocampal CA1 is crucial in the acquisition of morphine selfadministration in rats. Addiction Biology, pp 1-12. doi: 10.1111/adb.12730 https://www.ncbi.nlm.nih.gov/pubmed/30950138

Copyright (c) 2019 Society for the Study of Addiction; published by Wiley. Used by permission.

Submitted 22 June 2018; revised 11 January 2019; accepted 24 January 2019. 
role for one of the de novo DNA methyltransferase, DNMT3a, in the acquisition of morphine self-administration (SA) in rats. The expression of DNMT3a in the hippocampal CA1 region but not in the nucleus accumbens shell was significantly upregulated after 1 - and 7 -day morphine SA ( $0.3 \mathrm{mg} / \mathrm{kg} /$ infusion) but not after the yoked morphine injection. On the other hand, saccharin SA did not affect the expression of DNMT3a or DNMT3b. DNMT inhibitor 5-aza-2-deoxycytidine (5-aza) microinjected into the hippocampal CA1 significantly attenuated the acquisition of morphine SA. Knockdown of DNMT3a also impaired the ability to acquire the morphine SA. Overall, these findings suggest that DNMT3a in the hippocampus plays an important role in the acquisition of morphine SA and may be a valid target to prevent the development of morphine addiction.

Keywords: acquisition, DNMT3a, hippocampal CA1, morphine, self-administration

\section{Introduction}

Recent increase in opioid prescriptions is responsible for the upsurge in reported cases of drug overdose and opioid-related addiction. ${ }^{1}$ This epidemic has prompted researchers to look into the neurobiological mechanisms of opioid addiction. Behaviorally, it is well documented that environmental cues associated with drug use can enter into an association with the rewarding effects of drugs, becoming conditioned rewards to motivate drug seeking and taking behaviors. They can also trigger drug relapse in drug addicts. ${ }^{2}$ The strength of the cue-drug association appears to be higher than that of the cuenatural reward (e.g., food) association in controlling behaviors, ${ }^{3,4}$ owing to the fact that drugs of abuse often cause superphysiological changes in the brain reward systems (e.g., the mesolimbic dopamine system) and induce longer-lasting molecular adaptations than those induced by natural rewards. ${ }^{5}$ For instance, drugs of abuse produce a much greater dopamine increase that does not habituate over time compared with natural rewards. ${ }^{6}$ This unique effect of drugs might facilitate dopamine activity and enhance synaptic plasticity in the hippocampus $C A 1^{7,8}$ and makes the cue-drug association much easily to be formed and harder to be extinguished.

Recent studies have highlighted the importance of DNA methylation, a stable chromatin modification catalyzed by DNA methyltransferases (DNMTs), ${ }^{9}$ in drug induced synaptic plasticity and drug addiction. ${ }^{10,11}$ Three DNMTs have been identified in mammalian cells: DNMT1 primarily methylate hemimethylated DNA, while DNMT3a and DNMT3b are de novo methyltransferases. ${ }^{12}$ The expressions of 
DNMT1, DNMT3a, and DNMT3b in the nucleus accumbens (NAc) are found to be altered after cocaine treatment. ${ }^{11,13}$ Furthermore, blocking DNA methylation in the NAc is shown to potentiate cocaine reward. ${ }^{11}$ Recently, DNA methylation has been reported to contribute to the incubation of cocaine craving ${ }^{14}$ and heritable cocaine-seeking motivation. ${ }^{15}$ Our previous studies also suggest that injection of DNMT inhibitor into the hippocampal CA1 region impairs the acquisition of cocaine-induced and morphine-induced conditioned place preference (CPP). ${ }^{16,17}$ Collectively, these findings suggest that DNMTs may be critical for the acquisition of cue-drug association.

Operant conditioning linking environmental cues with a drug reward cause long-lasting pathological alterations in both reward and learning circuits. ${ }^{18}$ The NAC and hippocampus CA1 have been identified as key brain areas involved in this type of learning. The NAc shell is targeted by drug rewards ${ }^{19-21}$ and food rewards, ${ }^{22,23}$ while the hippocampus plays an important role in the acquisition of drug conditioned behaviors, such as cocaine-induced and morphine-induced CPP and self-administration (SA). Studies show that injection of dopamine receptor antagonists into the CA1 region impairs the acquisition of morphine-induced CPP, ${ }^{24}$ and cocaine SA training causes change in neuronal morphology in the hippocampal CA1,25 and inhibition of cyclin-dependent kinase 5 in the dorsal hippocampus is able to enhance heroin SA. ${ }^{26}$ Furthermore, heroin SA is shown to increase the function of mu-opioid receptors in both the NAc and the hippocampus. ${ }^{27} \mathrm{Al}-$ though there is evidence that the formation of cue-drug association requires the transcriptional regulation in these brain regions, ${ }^{28}$ our understanding of the role of DNA methylation in the acquisition of drug $\mathrm{SA}$ is still inadequate.

In the present study, we used the morphine SA model in rats and examined the role of de novo DNMTs in the acquisition of this operant response. Our results show that the acquisition of morphine SA resulted in the overexpression of DNMT3a in the CA1 region of the hippocampus but not in the NAc shell. The DNMT3a expression was up-regulated only in the rats that acquired morphine SA but not in the yoked and morphine-matched control rats or in those saccharin SA rats. We also found that DNMT inhibition or DNMT3a knockdown in the CA1 impaired the acquisition of morphine SA. Overall, these findings indicate that DNMT3a play an important role in the acquisition of opiate operant conditioning. 


\section{Materials and Methods}

\subsection{Animals}

Eight- or nine-week-old male Sprague-Dawley rats (Charles River, Beijing, China) were used. They were individually housed in stainless metal mesh cage $(25 \mathrm{~cm} \times 22.5 \mathrm{~cm} \times 30 \mathrm{~cm})$ on 12-hour light/dark cycle with food and water ad libidum before morphine SA. A total of 181 rats were used, 3 rats died after surgery, 4 rats were excluded after histological evaluation of the infusion target, and 9 were excluded due to SA vein catheter blockage. Therefore, 165 rats were considered for final data analysis. The experimental procedures were carried out according to the guideline provided by the Regulation for the Administration of Affairs Concerning Experimental Animals (China, 1988). The experimental protocol was approved by Research Ethics Review Board of Institute of Psychology, Chinese Academy of Sciences.

\subsection{Jugular vein catheterization}

Rats were anesthetized with pentobarbital sodium (100 mg/kg). The silicone catheter (OD $1.0 \mathrm{~mm}$, ID $0.55 \mathrm{~mm}$ ) was implanted in a rat's right jugular vein and secured to the vein with silk sutures. The other side of the catheter was passed subcutaneously to the back where it exited into a connector (22-gauge cannula; Plastics One) sutured on skin. Rats were allowed to recover for 5 to 7 days before behavioral training. Catheters were flushed once daily with $0.4 \mathrm{~mL}$ of heparinized saline $(100 \mathrm{U} / \mathrm{mL})$ during the recovery days.

\subsection{Brain stereotaxic surgery}

Immediately after the jugular vein catheterization, a stereotaxic surgery was conducted for the rats that were used in the microinjection experiments. Stainless steel guide cannulas $(8 \mathrm{~mm}$ for the hippocampal CA $1 ; 11.5 \mathrm{~mm}$ for the NAc shell) were bilaterally implanted into the hippocampal CA1 (anteroposterior, $-3.6 \mathrm{~mm}$; mediolateral, \pm 1.7 $\mathrm{mm}$ to bregma; and dorsoventral, $-2.6 \mathrm{~mm}$ ) or NAc shell (anteroposterior, $+1.6 \mathrm{~mm}$; mediolateral, $\pm 0.8 \mathrm{~mm}$ to bregma; and dorsoventral, $-7.0 \mathrm{~mm}$ ) on a stereotactic device (RWD Life Science, Shenzhen, China). Figure 3 shows the sample image of placement of the guide 
cannula in the CA1 and the NAc shell. After surgery, rats were treated with a systemic antibiotic (16 $000 \mathrm{U} / \mathrm{rat}$, penicillin) daily during the recovery days (5-7 days).

\subsection{Microinjection of 5-Aza-2' -deoxycytidine}

The DNMT inhibitor 5-Aza-2'-deoxycytidine (5-aza, Sigma, St. Louis, MO, USA) was diluted in $0.8 \%$ acetate ( $0.9 \%$ sterile saline) to a concentration of $2 \mathrm{mg} / \mathrm{mL}$. Rats received bilateral microinjection of 5 -aza $(0.5 \mu \mathrm{L} / \mathrm{side})$ to the CA 1 or the NAc shell immediately before each morphine SA daily test session. The vehicle group received isovolumetric $0.8 \%$ acetic acid injection. Hamilton microsyringe $(10 \mu \mathrm{L})$ and a syringe pump (RWD Life Science, Shenzhen, China) were used to deliver 5 -aza or vehicle. The injection rate was $0.25 \mu \mathrm{L} / \mathrm{min}$ over 2 minutes, after which the injection needle remained in the guide cannula for another 2 minutes to prevent backflow. After injection, stainless plugs were put back into the guide cannula.

\subsection{Histology identification}

After the completion of all behavioral tests, rats were deeply anesthetized with chloral hydrate $(40 \mathrm{mg} / \mathrm{kg})$. Their brains were removed, postfixed with $4.0 \%$ paraformaldehyde in $0.01 \mathrm{M}$ phosphate buffer salt ( $\mathrm{pH}$ 7.4) for 24 hours, and dehydrated by $20 \%$ sucrose solution and $30 \%$ sucrose solution at $4{ }^{\circ} \mathrm{C}$ successively. Coronal sections (40$\mu \mathrm{m}$ thick) containing the cannula tracks were cut on a freezing microtome. Rats with cannula misplacement of the interest area were excluded from data analysis. The schematic representations of the intracranial cannula infusion sites are shown in Figure 3.

\subsection{Adeno-associated virus (AAV) preparation}

We used AAV2-Dnmt3a $\left(2.19 \times 10^{12} \mathrm{GC} / \mathrm{mL}\right)$ to knock down DNMT3a. The short-hairpin RNA (shRNA) recognizes DNMT3a sequence (GGAAGCGGAGTGTGGAATTTA), while the scrambled sequence for the control AAV2 $\left(3.69 \times 10^{12} \mathrm{GC} / \mathrm{mL}\right)$ is CCTAAGGTT AAGTCGCCCTCG. For the expression of shRNA, we used a vector containing the human $U 6$ promoter upstream of the shRNA sequence and the human phosphoglycerate kinase promoter to drive EGFP. The viruses were designed 
and assembled by Cygen (Guangzhou, China). The in vivo validation of AAV2-Dnmt3a is shown in Figure 5E.

\subsection{AAV microinjection}

AAV2-Dnmt3a and AAV2-Control were bilaterally microinjected into the hippocampal CA1 (1.0 $\mu \mathrm{L} /$ side) based on the published studies. 29-31 We used the same coordinates mentioned above. Injections were made by using a $10-\mu \mathrm{L}$ Hamilton syringe controlled by a syringe pump (RWD, Shenzhen, China). We delivered the AAVs at a rate of $0.1 \mu \mathrm{L} /$ minutes over 10 minutes. After injection, the injection needle was left in place for an additional 10 minutes to allow diffusion. Behavioral or western blot experiments were performed 4 weeks after the stereotaxic delivery of AAVs.

\subsection{Apparatus}

The SA was conducted in eight operant chambers (AniLab, Ningbo, China). Each chamber $(29 \times 29 \times 26 \mathrm{~cm})$ was housed in an opaque sound-proof box equipped with an exhaust fan. Each chamber had a white house light for illumination. Two holes, placed at $5 \mathrm{~cm}$ above the grid floor, were used to record "nose poking." A yellow cue light was placed inside each hole. A buzzer, located outside of the chamber, was used to provide the audio cue. The vein catheter of a rat was connected to a pump-driven syringe (infusion speed, $20 \mu \mathrm{L} / \mathrm{s}$ ). Data were collected with PC Windows-compatible AniLab software (AniLab, Ningbo, China).

\subsection{Morphine SA training and testing}

Rats were trained to self-administer morphine for 3 hours/day under a fixed-ratio- 1 schedule with 20 -second timeout. The training occurred in the dark cycle for 1 day or 7 days. We set one nose-poke hole as active and the other as inactive. The house light was turned on at the beginning of each session to indicate the availability of morphine. Rats received an intravenous morphine infusion $(0.3 \mathrm{mg} / \mathrm{kg}, 0.1 \mathrm{~mL}, 5 \mathrm{~s} / \mathrm{in}$ fusion) when they poked the active hole. This response also simultaneously activated a compound 5-second tone-light cue and turned 
the houselight off for 20 seconds. No programmed event happened during the 20 -second timeout period even though rats may still poke the active hole. Poking the inactive hole did not trigger morphine infusion or the presentation of conditioned cues. We set 60 infusions as the maximum for 3-hour session to prevent overdose. Yoked rats received passive noncontingent morphine injections in an identical temporal pattern as their morphine self-administering partners but did not receive the infusion cues with each nose-poke. Rats were fed daily with 20-g chow during morphine SA. ${ }^{32}$ Catheters were flushed twice daily with $0.2 \mathrm{~mL}$ of heparinized saline $(100 \mathrm{U} / \mathrm{mL})$. The number of active and inactive nose-pokes (NP) was recorded.

\subsection{Saccharin SA}

Rats were trained to self-administer $0.2 \%$ saccharin solution for 1 hour per day under a fixed-ratio-1 with 20-second timeout schedule for 1 day or 7 days. Other training conditions for saccharin SA were similar to those for morphine SA except that a liquid receptacle was placed between the nose-poke holes and there was no limit on the maximum number of saccharin intakes. Yoked control rats also received passive noncontingent saccharin liquids in an identical temporal pattern as their saccharin self-administering partners but did not receive the conditional cues with each nose-poke.

\subsection{Brain tissue dissection}

Rats were decapitated immediately after morphine or saccharin SA, and the brains were removed and submerged in optimal cutting temperature compound (SAKURA Tissue-Tek 4583, USA) in tinfoil vessels. Then, the brains were quick-frozen by liquid nitrogen. We dissected out the CA1 and the NAc shell in freezing microtome (Leica, Germany) by using a punch tool (1-mm inner diameter).

\subsection{Western blotting}

Crude protein lysates were generated by ultrasonication of brain tissue in RIPA buffer containing a $2 \times$ concentration of Halt Protease and $1 \times$ Phosphatase Inhibitor (Applygen, China) cocktail and 
centrifuged for 10 minutes at $12000 \mathrm{~g}$ at $4^{\circ} \mathrm{C}$. Protein concentrations in the supernatant (extract) were measured by the Pierce BCA Protein Assay Kit (ThermoFisher, USA). Equal amount of total protein $(30 \mu \mathrm{g})$ was loaded in sodium dodecyl sulfate polyacrylamide gel electrophoresis gel. After electrophoresis, proteins were transferred onto polyvinylidene fluoride (PVDF) membrane (Merck, Germany). The PVDF membrane was cut into horizontal stripes according to different molecular weights of target proteins, as indicated by marker (Thermo Scientific, USA). We then made PVDF membrane stripe containing only one target protein probed with the homologous primary antibodies in $0.1 \%$ TBST at $4^{\circ} \mathrm{C}$ overnight. Primary antibodies included rabbit anti-DNMT3a antibody (1:2000, Abcam, ab188470), rabbit anti- DNMT3b antibody (1:1000, Abcam, ab79822), and mouse anti- $\beta$-actin (1:3000, Sigma, A2228). Then the PVDF membrane was incubated with secondary antibodies (goat antirabbit: 1:2000, ZSGBBIO, ZB2301; goat antimouse: 1:2000, ZSGB-BIO, ZB-2305) in 0.1\% TBST for 1 hour at room temperature. The blots were then incubated with a layer of enhanced chemiluminescence substrate (Detection Reagents 1 and 2, 1:1 ratio, Applygen, China) for 90 seconds at room temperature. The membranes were imaged using FluorChem E system (Protein simple, America). Densitometry was used to calculate the band intensity. The optical densities were normalized to $\beta$-actin protein expression to control for inconsistencies between the loaded samples. The data showed in figures were normalized to the naïve rats.

\subsection{Statistical analysis}

Data are expressed as mean \pm SEM, and all statistical analyses were performed using GraphPad Prism version 6.00 for Windows. Two-way analysis of variance (ANOVA) was used to analyze the behavioral and western blot data, followed by Bonferroni post hoc analysis if necessary. Student's $t$ test was used to examine the knocking-down efficiency of AAV-DNMT3a. For clarity, we indicate the between- and within-subject factors of the different analyses in Section 3. Statistical significance was set at $P<0.05$. 


\section{Results}

\subsection{Morphine SA up-regulated the expression of DNMT3a in the CA1}

Among the three groups of rats used in this experiment (Figure 1A), only those trained in morphine SA acquired this operant response after 7-day training (Figure 1B). ANOVA with nose-poke (active vs. inactive) as the between-subjects factor and training day (seven levels) as the within-subjects factor showed a main effect of nose-poke $\left(F_{1}\right.$ $\left.{ }_{130}=131.50, P<0.001 ; n=9-18\right)$ and nosepoke $\times$ training day interaction $\left(\mathrm{F}_{6,130}=3.55, P<0.01\right)$, but no main effect of training day $\left(\mathrm{F}_{6}\right.$, ${ }_{130}=0.77, P=0.59$ ). Post hoc comparisons revealed that rats poked the active hole significantly more than the inactive one beginning on the second day $(P<0.01)$.

On the DNMT expression in the CA1, ANOVA with treatment (naïve, SA morphine, Yoked morphine) as the between-subjects factor and training day (two levels) as the within-subjects factor showed a main effect of treatment $\left(\mathrm{F}_{2,43}=10.11, P<0.001\right)$, but no main effect of training day $\left(\mathrm{F}_{1,43}=0.77, P=0.38\right)$, or treatment $\times$ training day interaction $\left(F_{2,43}=1.14, P=0.33\right)$. Post hoc test showed that DNMT3a expression in the CA1 increased after morphine SA training compares with the naïve group. This effect appeared after 1 day or 7 days of training ( 1 day: $P<0.05, n=8-9$ per group; 7 days: $P<0.01, \mathrm{n}=9$ per group; Figure 1C). The DNMT3a expression was also increased in the morphine SA group compared with the yoked group after 7 days but not after 1 day of training ( 1 day: $P=0.81, n=7-8$ per group; 7 days: $P<0.01, n=7-9$ per group; Figure $1 C$ ). DNMT3a expression in the yoked morphine group did not significantly differ from the naïve group ( 1 day: $P=0.31, \mathrm{n}=7-9$ per group; 7 days: $P>0.99, \mathrm{n}=7-9$ per group).

For the DNMT3a expression in the NAc shell, statistical analysis did not find any effect of treatment $\left(F_{2,44}=0.83, P=0.44\right)$, training day $\left(\mathrm{F}_{1,44}=2.54, P=0.12\right)$, or treatment $\times$ training day interaction $\left(\mathrm{F}_{2,44}=\right.$ $0.66, P=0.52 ; \mathrm{n}=7-9$ per group; Figure 1D).

For the DNMT3b expression in the CA1 and in the NAc shell, statistical analysis did not find a main effect of treatment $\left(C A 1: F_{2,44}=0.82\right.$, $P=0.92, \mathrm{n}=7-9$ per group; Figure $1 \mathrm{E} ; \mathrm{NAc}$ shell: $\mathrm{F}_{2,44}=0.31, P=0.73$, 
A

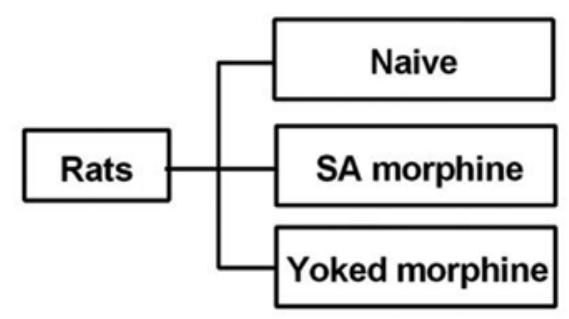

C
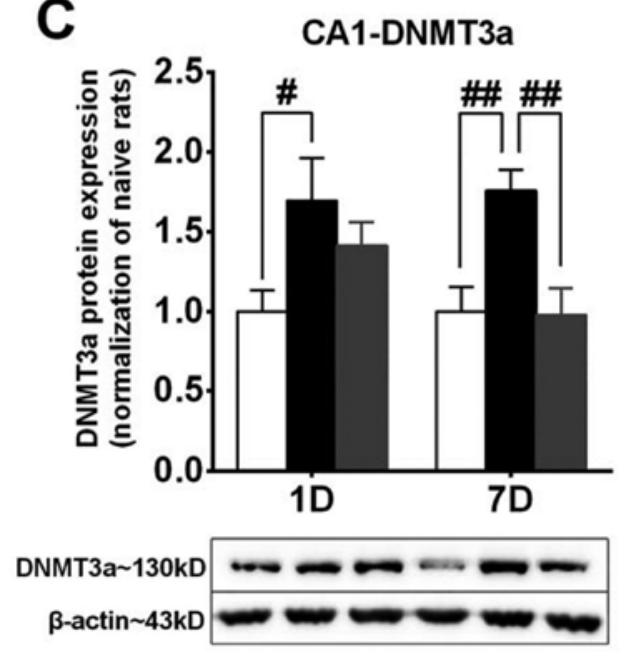

E

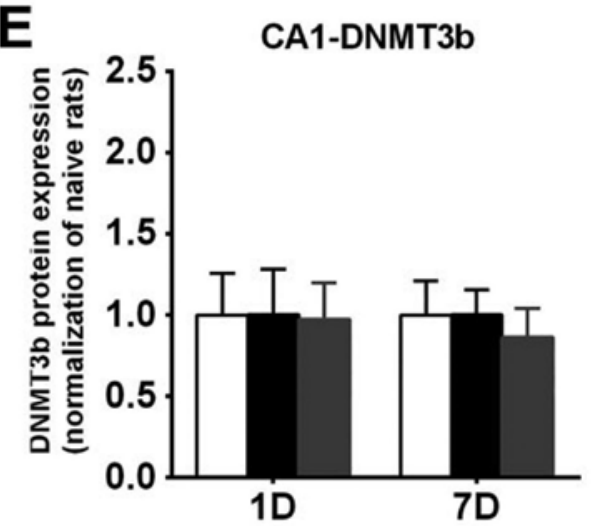

DNMT3b 96kD

$\beta$-actin $\sim$ 43kD
B

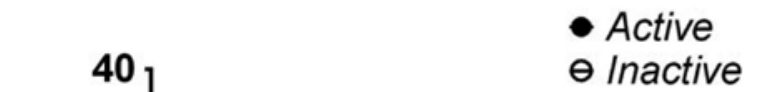

D

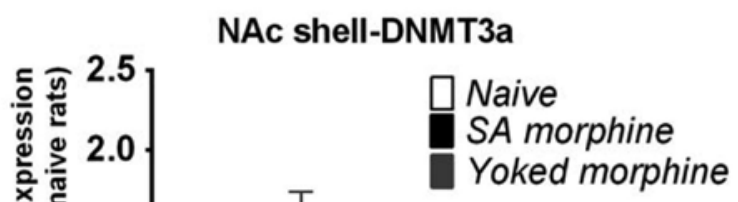

F

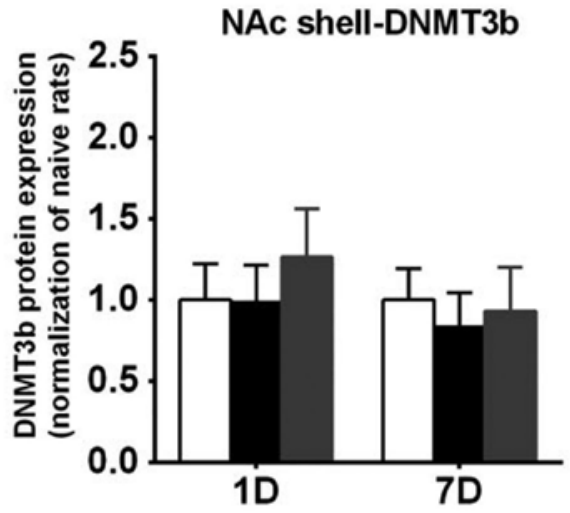

DNMT3b 96kD $\beta$-actin 43kD

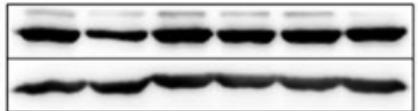


Figure 1. The expression of DNMT3 after 1- or 7-day morphine self-administration (SA) training and yoked control. A, The group information. B, Rats acquired morphine SA after 7 days of training $(n=9-18)$. DNMT3a expression of morphine SA and yoke control group in the CA1 (C) and the NAc shell (D) $(n=7-9)$. DNMT3b expression of morphine SA and yoke control group in the CA1 (E) and the NAc shell (F) $(\mathrm{n}=7-9)$. Data are presented as mean $\pm \mathrm{SEM},{ }^{* *} P<0.01,{ }^{* \star *} P<0.001$ vs. inactive nose-pokes; ${ }^{\#} P<0.05$ vs. naive group, ${ }^{\# \# P}<0.01$ vs. naive group or yoked morphine group

$\mathrm{n}=7-9$ per group; Figure $1 \mathrm{~F})$, training day (CA1: $F_{1,44}=0.04, P=0.84$, $\mathrm{n}=7-9$ per group; Figure 1E; NAc shell: $\mathrm{F}_{1,44}=0.71, P=0.41, \mathrm{n}=7-9$ per group; Figure $1 \mathrm{~F})$, or treatment $\times$ training day interaction $\left(\mathrm{CA} 1: \mathrm{F}_{2}\right.$, ${ }_{44}=0.04, P=0.96, \mathrm{n}=7-9$ per group; Figure $1 \mathrm{E} ; \mathrm{NAc}$ shell: $\mathrm{F}_{2,44}=0.24$, $P=0.79, \mathrm{n}=7-9$ per group; Figure 1F).

In summary, we showed that rats acquired morphine SA, and this operant behavior was associated with an up-regulated DNMT3a in the CA1, indicating that DNMT3a in the CA1 is specifically involved in the acquisition of morphine SA.

Saccharin SA had no significant effect on the expression of DNMTs in the CA1 or the NAc shell.

To clarify whether the up-regulation of DNMT3a in the CA1 was specific to morphine SA, we used saccharin SA to simulate operant learning with natural reward and examined the expression of DNMT3. Among the three groups tested (Figure 2A), only the conditioned group acquired saccharin SA after 7 days of training (Figure 2B). There was a main effect of nose-poke (active vs inactive) $\left(F_{1,820}=319, P<\right.$ $0.001 ; n=6-12)$, nose-poke $\times$ training day interaction $\left(F_{6,820}=13.56\right.$, $P<0.001)$, and a main effect of training day $\left(F_{6,820}=13.56, P<0.001\right)$. Post hoc comparisons revealed that rats poked the active hole significantly more than the inactive hole beginning on the second day of training $(P<0.001)$.

For the DNMT3a expression in the CA1, statistical analysis did not find a main effect of treatment (naïve, SA saccharin, Yoked saccharin) $\left(F_{2,29}=1.20, P=0.32\right)$, training day $\left(F_{1,29}=1.36, P=0.25\right)$, or treatment $x$ training day interaction $\left(F_{2,29}=2.37, P=0.11, n=5-6\right.$ per group; Figure $2 \mathrm{C}$ ). For the DNMT3a expression in the NAc shell, statistical analysis showed a main effect of training day $\left(\mathrm{F}_{1,29}=5.25, P<0.05\right)$, but no main effect of treatment $\left(F_{2,29}=2.97, P=0.07\right)$ or treatment $x$ 
A

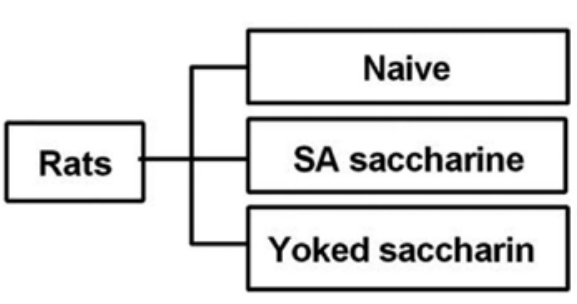

C
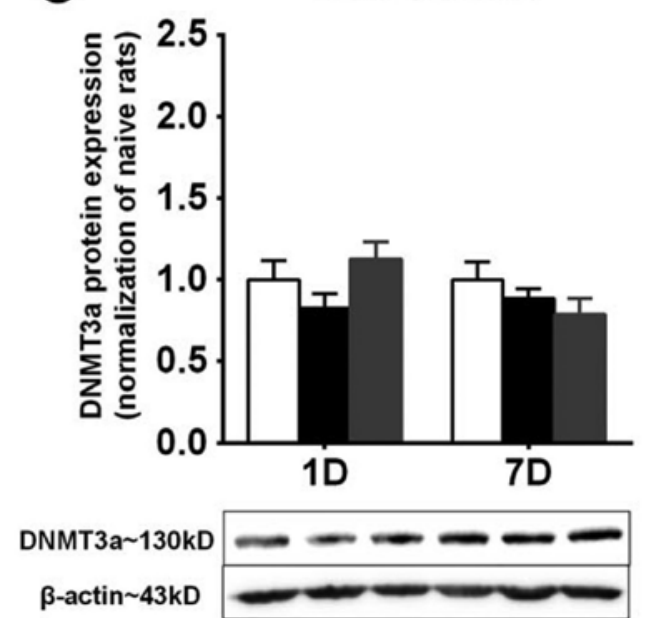

E

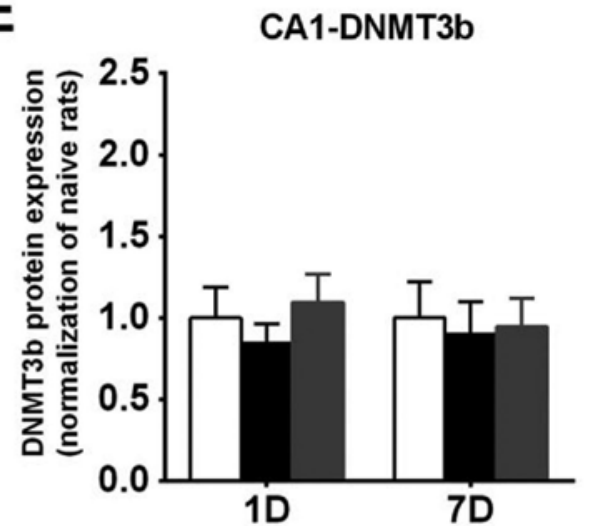

DNMT3b $\sim 96 \mathrm{kD}$ $\beta$-actin $\sim 43 \mathrm{kD}$

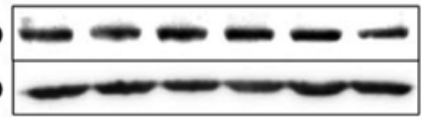

B

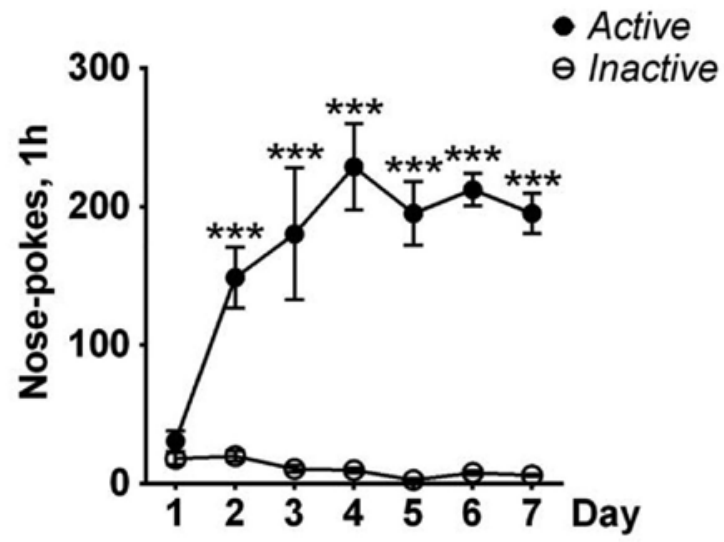

D
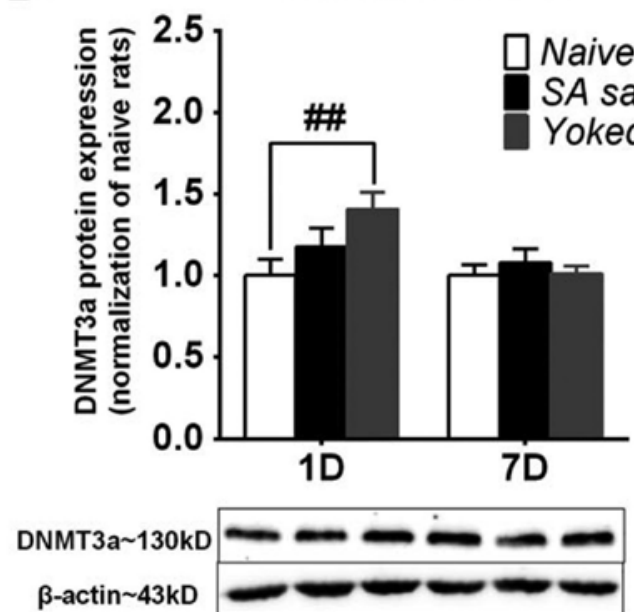

$F$

NAc shell-DNMT3b

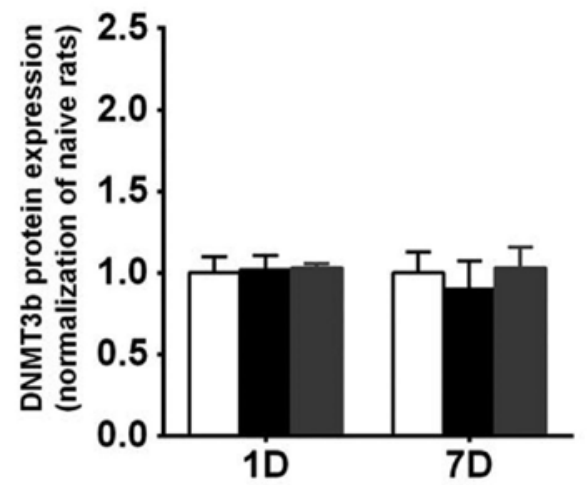


Figure 2. The expression of DNMT3 after 1- or 7-day saccharin self-administration (SA) training and yoked control. A, The group information. B, Rats acquired saccharin SA after 7 days of training $(n=6-12)$. DNMT3a expression of saccharin SA and yoke control group in the CA1 (C) and the NAc shell (D) $(n=5-6)$. DNMT3b expression of saccharin SA and yoke control group in the CA1 (E) and the NAc shell (F) (n $=6$ ). Data are presented as mean $\pm \mathrm{SEM},{ }^{* * *} P<0.001$ vs. inactive nose-pokes; ${ }^{\# \#} P$ $<0.01$ vs. naive group

training day interaction $\left(F_{2,29}=2.86, P=0.07\right)$. Post hoc test showed that saccharin SA did not affect DNMT3a expression compared with the naïve group ( 1 day: $P>0.99, n=6$ per group; 7 days: $P>0.99$, $\mathrm{n}=5-6$ per group; Figure 2D). Interestingly, DNMT3a in the yoked saccharin group showed increased expression compare to the naïve group after 1 day of training $(P<0.01)$ but not after 7 days $(P>0.99)$.

For the DNMT3b expression in the CA1 and in the NAc shell, statistical analysis did not show a main effect of treatment (CA1: $F_{2,30}=$ $0.39, P=0.68, \mathrm{n}=6$ per group; Figure 2E; NAc shell: $\mathrm{F}_{2,29}=0.31, P=$ $0.84, \mathrm{n}=6$ per group; Figure $2 \mathrm{~F})$, training day $\left(\mathrm{CA} 1: \mathrm{F}_{1,30}=0.04, P=\right.$ $0.84, \mathrm{n}=6$ per group; Figure 2E; NAc shell: $F_{1,29}=0.17, P=0.6872$, $\mathrm{n}=6$ per group; Figure $2 \mathrm{~F}$ ), or treatment $\times$ training day interaction (CA1: $\mathrm{F}_{2,30}=0.17, P=0.84, \mathrm{n}=6$ per group; Figure $2 \mathrm{E} ; \mathrm{NAc}$ shell: $\mathrm{F}_{2,29}$ $=0.17, P=0.84, \mathrm{n}=6$ per group; Figure $2 \mathrm{~F}$ ).

Neither DNMT3a expression nor DNMT3b expression in the CA1 significantly changed after 1 day or 7 days of 3-hour saccharin SA training (see Figure S1 in the Supporting Information).

These data suggest that saccharin SA had no significant effect on the expression of DNMT3 in either the CA1 or NAC shell. The upregulation of DNMT3a in the CA1 may be specific to the morphine SA.

Microinjection of 5-aza into the CA1 inhibited the acquisition of morphine SA.

In order to demonstrate the causal role of DNMTs in the acquisition of morphine SA, we microinjected the DNMT antagonist 5-aza or vehicle into the CA1 or the NAc shell before each daily training session and examined whether 5 -aza would alter the acquisition of morphine SA. Figure 3 shows the sample images of guide cannula placement in the CA1 and the NAc shell. For the vehicle-CA1 group (Figure $4 A$ ), two-way ANOVA revealed a main effect of nose-poke (active vs. 

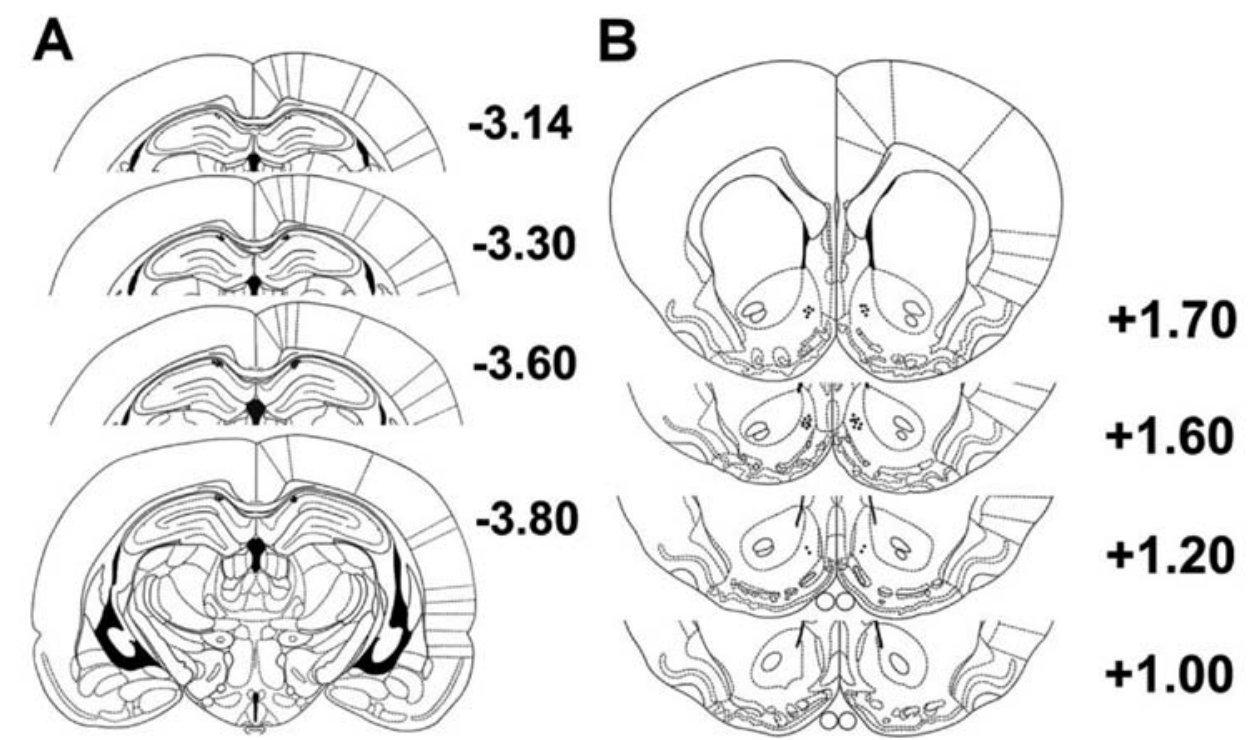

Figure 3. Schematic representations of the intracranial cannula infusion sites in the hippocampal CA1 (A) and the NAc shell (B). Numbers besides the sections indicate anteroposterior distance from bregma in millimeters.

inactive, $\left.\mathrm{F}_{1,220}=44.45, P<0.001\right)$ and nose-poke $\times$ training day interaction $\left(\mathrm{F}_{6,132}=2.33, P<0.05, n=12\right)$. Post hoc comparisons revealed that there were more active NP than inactive NP beginning on the third day $(P<0.001)$. For the vehicle-NAc shell group, two-way ANOVA also revealed a main effect of nose-poke $\left(F_{1,140}=45.67, P<\right.$ $0.001)$ and nose-poke $\times$ training day interaction $\left(F_{6,840}=2.43, P<0.05\right.$, $n=7$; Figure 4B). Again, there were significantly more active NP than the inactive NP since the second day $(P<0.01)$. These results suggest that both vehicle groups acquired the morphine SA successfully.

For the 5-aza-CA1 group (Figure 4C), two-way ANOVA did not find any significant effect of nose-poke $\left(F_{1,20}=2.60, P=0.12\right)$, nor nosepoke $\times$ training day interaction $\left(\mathrm{F}_{6,120}=0.29, P=0.94, n=11\right)$. For the 5 -aza-NAc shell group (Figure 4D), two-way ANOVA only revealed a main effect of nose-poke $\left(\mathrm{F}_{1,120}=21.64, P<0.001\right)$, but no significant effect of training day $\left(\mathrm{F}_{6,720}=0.76, P=0.60\right)$ nor their interaction $\left(\mathrm{F}_{6}\right.$, $720=0.83, P=0.55, n=8)$. Post hoc comparisons revealed that there were significantly more active NP than the inactive NP in this group on the second and fourth to seventh days $(P<0.05, \mathrm{n}=8)$. These results suggest that microinjection 5-aza into the CA1 not into the NAC shell inhibited the acquisition of morphine SA. 


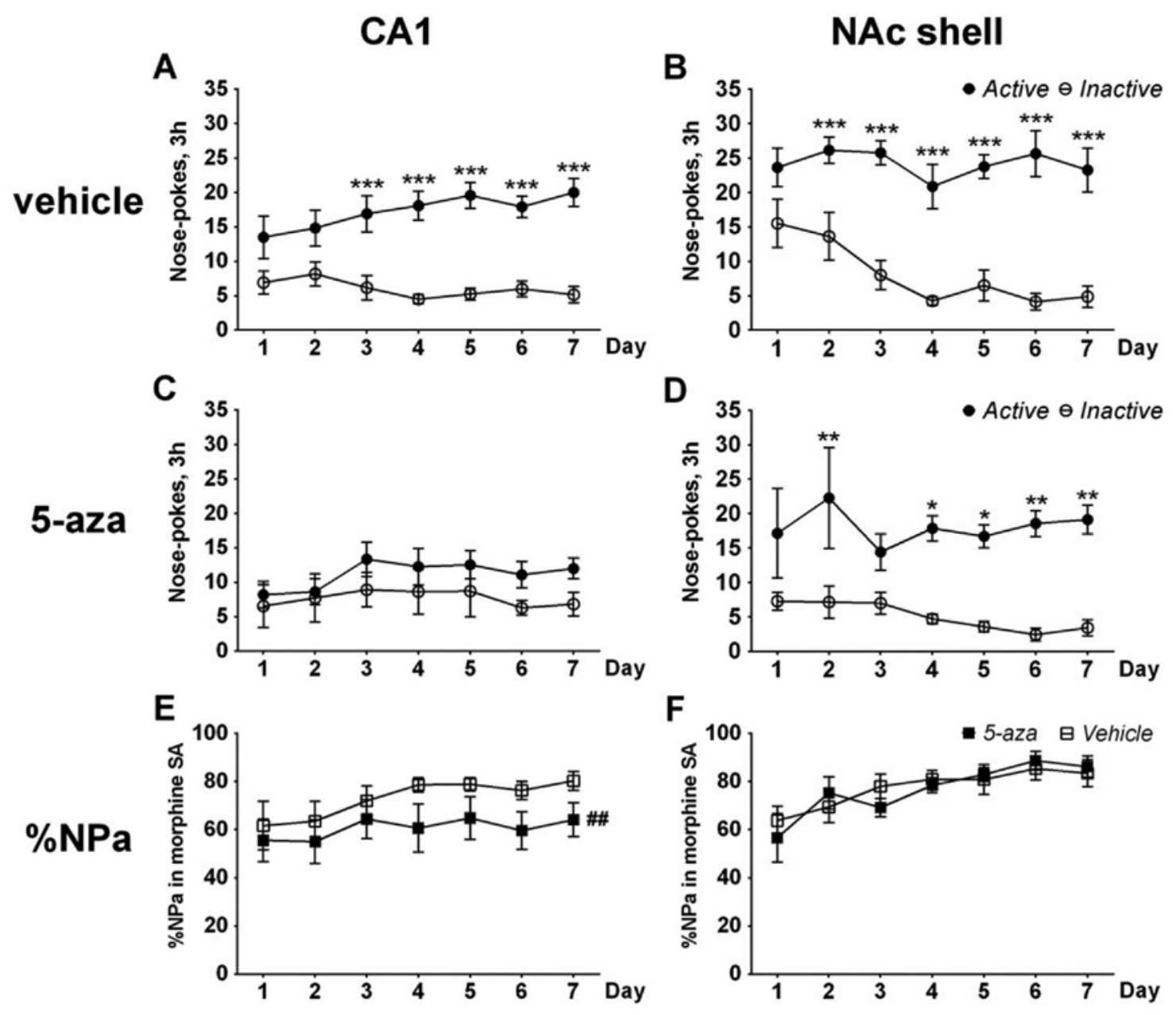

Figure 4. Effect of microinjection of a DNA methyltransferase inhibitor 5 -aza (1 $\mu \mathrm{g} /$ side) on the acquisition of morphine self-administration (SA). Microinjection of vehicle into the CA1 (A) or NAc shell (B) had no significant effect on the acquisition of morphine SA. Microinjection of 5-aza into the CA1 (C) inhibited the acquisition of morphine SA while microinjection 5-aza into the NAc shell (D) had no significant effect on the acquisition of morphine SA. E,F, Percentage of nose-pokes in the active hole $(\% \mathrm{NPa})$ performed during the 7 -day morphine SA. Microinjection of 5 -aza into CA1 (E) inhibited the \%NPa, while microinjection of 5-aza into NAc shell (F) did not. Data are presented as mean \pm SEM $, n=7-12 .{ }^{*} P<0.05,{ }^{* *} P<0.01,{ }^{* \star *} P<0.001$ vs. inactive nose-pokes. ${ }^{\#} P<0.01$ vs. vehicle group

In order to compare the 5-aza and vehicle groups directly, we calculated the percentage of NP in the active hole (\%NPa) of both groups (\%NPa $=$ the number of active NP/[the number of active NP + the number of inactive NP]). The $\% \mathrm{NPa}$ of the vehicle group was $60 \%$ at 
the beginning and gradually increased to $80 \%$ at the end of morphine SA (Figure 4E and 4F). After 5-aza was microinjected into the CA1, the $\%$ NPa was maintained at $60 \%$ throughout the 7 -day morphine SA. ANOVA with treatment (5-aza, vehicle) as the between-subjects factor and training day (7 levels) as the within-subjects factor showed that the \%NPa of the vehicle group was higher than the \%NPa of the 5-aza group (Figure 4E; a main effect of treatment: $F_{1,147}=10.09, P<$ 0.01; no treatment $\times$ training day interaction: $F_{6,147}=0.23, P=0.97$; no main effect of training day: $F_{6,147}=1.18, P=0.32$ ). Microinjection of 5aza into the NAc shell did not change the \%NPa significantly (Figure 4F; treatment effect: $F_{1,910}=0.05, P=0.83$; treatment $\times$ training day interaction: $F_{6,910}=0.51, P=0.80$; training day effect: $F_{6,910}=5.54, P$ $<0.001)$. These results suggest that antagonizing DNMTs in the CA1, but not in the NAc shell, inhibited the acquisition of morphine SA.

To confirm that the effect of 5-aza on the acquisition is mediated by DNMT inhibition, we microinjected another DNMT inhibitor RG108 into the CA1 before each daily training session and found that compared with vehicle treatment, RG108 inhibited the acquisition of morphine SA (see Figures S2 and S3).

Knocking-down DNMT3a in the CA1 inhibited the acquisition of morphine SA.

To further validate the causal impact of DNMT3a on the acquisition of morphine SA, we microinjected AAVs into the CA1 to knockdown DNMT3a and examined whether this manipulation altered the acquisition of morphine SA (Figure. 5). We used AAV, which contained a scrambled shRNA as the control AAV. The schematic representation is showed in Figure 5A. We validated the effectiveness of AAVDNMT3a expression in the CA1 28 days after microinjection (Figure 5B and $5 C$ ) by immunoblotting in naïve rats and found that AAV-DNMT3a knocked-down DNMT3a successfully compared with the control group ( $t=3.01, P<0.05, n=4-7$; Figure 5E).

We microinjected AAV in the CA1 28 days before the morphine SA training (Figure 5D). For the AAV-Control group (Figure 5F), two-way repeated measures ANOVA showed a main effect of nose-poke (active vs inactive) $\left(F_{1,280}=41.97, P<0.001 ; n=15\right)$, training day $\left(F_{6,168}\right.$ $=2.35, P<0.05)$, and their interaction $\left(F_{6,168}=5.65, P<0.001\right)$. Post hoc comparisons revealed that the number of active NP was significantly higher than that of the inactive NP beginning on the second 
A AAV2-DNMT3a

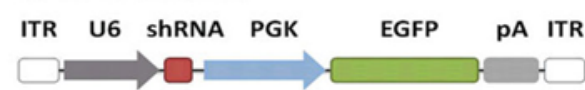

B

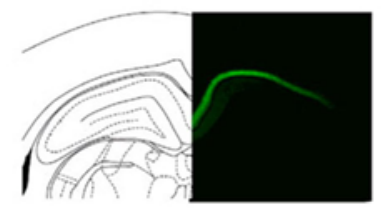

C AAV microinjection

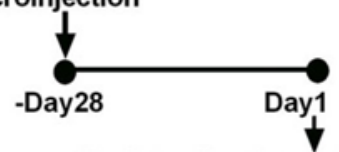

Nuclei collection and western blot

D AAV

microinjection

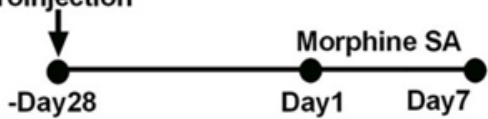

E

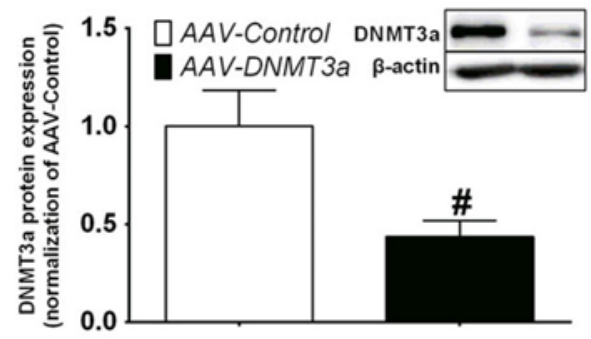

F

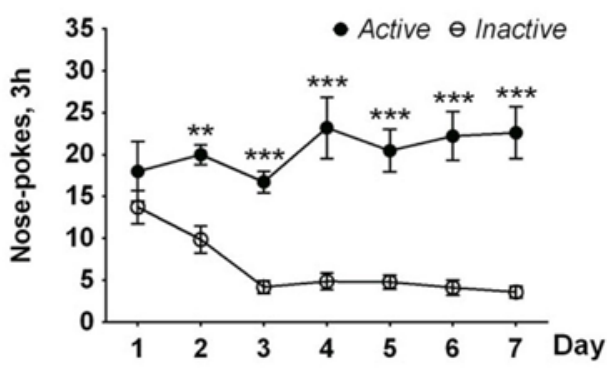

G

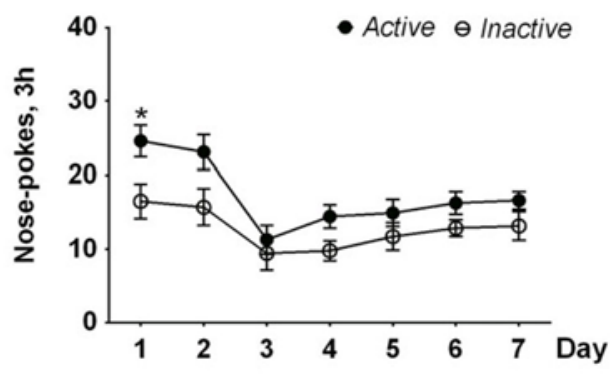

H $\% \mathrm{NPa}$

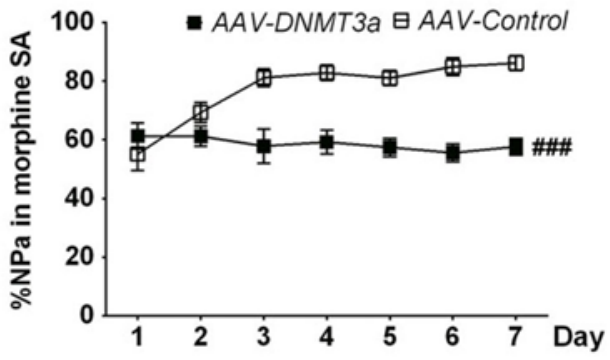

Figure 5. Effect of knocking down DNMT3a expression in the CA1 on the acquisition of morphine SA. A, The schematic representation of adeno-associated virus (AAV)-DNMT3a. ITR, inverted terminal repeat; U6, human U6 promoter; shRNA, short hair-pin RNA; PKG, human phosphoglycerate kinase promoter; EGFP, EGFP reporter gene; PA, SV40 late polyadenation signal. B, Representative pictures of brain slices from rat injected with AAV-DNMT3a. C, The experimental timeline of detecting the efficiency of AAV-DNMT3a. D, The experimental timeline of AAV microinjection and morphine SA. E, AAV-DNMT3a can knock-down DNMT3a expression. F, Microinjection AAV-Control into the CA1 had no significant effect on the acquisition of morphine SA. G, Microinjection of AAV-DNMT3a into the CA1 inhibited the acquisition of morphine SA. $\mathrm{H}$, Percentage of nose-pokes in the active hole (\%NPa) performed during the 7-day morphine SA. Knocking down DNMT3a in CA1 inhibited the \%NPa. Data are presented as mean $\pm \mathrm{SEM}, n=14-15 .{ }^{\#} P<0.05$, ${ }^{\# \# \#} P<0.001$ vs. AAV-Control; ${ }^{*} P<0.05,{ }^{* *} P<0.01,{ }^{* \star *} P<0.001$ vs. inactive nosepokes 
day $(P<0.01)$, suggesting that the AAV-Control group acquired the morphine SA successfully. For the AAV-DNMT3a group (Figure 5G), two-way ANOVA revealed a main effect of nose-poke $\left(F_{1,260}=6.87\right.$, $P<0.05)$, but no significant nose-poke $\times$ training day interaction $\left(F_{6}\right.$, ${ }_{156}=1.06, P=0.39, n=14$ ). Post hoc comparisons revealed that the number of active NP was significantly higher than that of the inactive NP but only on the first day $(P<0.05)$.

ANOVA with treatment (AAV-DNMT3a, AAV-Control) as the between-subjects factor and training day (seven levels) as the withinsubjects factor showed that the \%NPa of the AAV-DNMT3a group was significantly lower than that of the AAV-Control group, indicating that AAV-DNMT3a inhibited the \%NPa of morphine SA (Figure $5 \mathrm{H}$; treatment: $\mathrm{F}_{1,189}=89.31, P<0.001$; treatment $\times$ training day interaction: $F_{6,189}=6.18, P<0.001$; and training day: $F_{6,189}=3.35, P<$ 0.001). Once again, knocking-down of DNMT3a in the CA1 inhibited the acquisition of morphine SA.

\section{Discussion}

The present study utilized a variety of behavioral and neuroscience tools and demonstrated that morphine SA, but not noncontingent passive morphine infusion (Figure $1 \mathrm{C}$ to $1 \mathrm{~F}$ ), selectively up-regulated the expression of DNMT3a in the CA1 (not in the NA shell), but had no effect on DNMT3b expression in both regions. Furthermore, the finding that saccharin SA had no effect on the expression of DNMTs in both the CA1 and NAc shell suggests that this up-regulation of DNMT3a in the CA1 was a morphine SA-specific effect, not just the result of any operant conditioning in response to a reward. We further showed that inhibition of DNMTs by 5-aza or knocking down the DNMT3a by AAV in the CA1 during the SA training period suppressed the acquisition of morphine $\mathrm{SA}$, demonstrating a causal role of CA1 DNMT3a in the mediation of the acquisition of morphine SA. Overall, our data strongly suggest that the DNMT3a in the CA1 is one of the critical mechanisms underlying the acquisition of morphine SA.

Identifying the neurobiological substrates that are differentially affected by drugs of abuse and natural rewards is critical for our understanding of the neurobiology of drug addiction and its treatment. 
Previous studies show that the subthalamic nucleus exerts opposite effects on cocaine and natural rewards, ${ }^{33}$ and the dorsomedial striatum is differentially impacted by cocaine SA and sucrose SA. ${ }^{34}$ Moreover, the NAc neurons differentially encode goal-directed behaviors about drugs of abuse and natural rewards. ${ }^{35,36}$ Our previous study also reports that inhibition of NMDA receptors potentiated the expression of food-induced CPP, but impaired that of morphine-induced CPP. ${ }^{37}$ Here, we show that DNMT3a was up-regulated in the CA1 after morphine SA but not saccharin SA, suggesting that DNMT3a may be differentially targeted by morphine and saccharin.

One important question is whether this epigenetic modification is specifically induced by the drug itself, or operant responding, or both. To control for the drug specific effect, we examined the expression of DNMT3a/3b in morphine SA and saccharin SA. Our results showed that 1 or 7 days of morphine SA up-regulated the expression of DNMT3a in the CA1, but saccharin SA did not. The parsimonious explanation is that morphine SA promotes dopamine neuronal excitation and produces a much greater dopamine increase than saccharin $\mathrm{SA}^{38}$ which might facilitate dopamine activity and enhance long-term potentiation in the CA1.7,8 Thus, DNA methylation may be involved in the development of drug-cue association, which is unusually stronger than the natural reward-cue association. ${ }^{3,4}$ Consistent with this possibility, memory about morphine SA appears to be more stable than the food memory, and stable memory may depend on long-lasting changes in synaptic plasticity through regulation of gene expression. ${ }^{28}$ It has been reported that the DNA methylation of calcineurin can persist for at least 30 days and is required for remote fear memory. ${ }^{39}$ Furthermore, there are reports indicating that the formation of stimulus-reward associative memories or fear memory causes DNA methylation in the ventral tegmental area and the CA1/anterior cingulate cortex, respectively. ${ }^{22,40}$ This current study extends these studies and provides new evidence that DNA methylation is also involved in the acquisition of morphine SA. Our findings also suggest that the DNA methylation resulted from the drug-related learning and memory but not from the drug itself, as the yoked morphine rats did not show such an effect. The results that DNMT3a was up-regulated in the CA1 but not the NAc shell also suggest that this up-regulation of DNMT3a is regional specific. 
Similar epigenetic impairments have been reported in the striatum of drug addicts and heroin SA rats. ${ }^{41}$ The NAc consists of the NAC shell and NAc core subregion. Both subregions are part of neuronal circuits involved in distinctive process in the development of drug addiction. ${ }^{42-44}$ Previous studies show that acute morphine or heroin injection increased extracellular DA selectively in the NAc shell, ${ }^{45}$ while D1 receptor blockade in the NAc shell but not in the NAc core impaired the acquisition of morphine-induced CPP. ${ }^{20}$ In the drug SA paradigm, cognitive processes seem to drive long-term genomic responses in the NAc shell, whereas the pharmacological actions of drugs of abuse (e.g., heroin) are mediated by the NAc core. ${ }^{46}$ Lecca et al also found that cocaine SA increased extracellular DA in the NAc shell significantly more than that in the NAc core. ${ }^{20}$ Moreover, optical stimulation of medium spiny neurons in the NAc shell could reinforce instrumental response. ${ }^{47}$ Based on these findings, in the present study, we focused only on the NAc shell but not the NAc core. One recent study also shows that DNMT3a2 expression in the NAc shell but not in the NAc core is involved in conditioned reinstatement and incubation of cocaine SA. ${ }^{48}$ Another interesting finding is that immediately after SA training, neither morphine SA nor saccharin SA affected the DNMT3a expression in the NAc shell. Previous studies show that cocaine SA alters the expression of DNMT in the NAc at 4 hours or later after the last cocaine injection. ${ }^{11,49}$ Anier et al ${ }^{13}$ reported that repeated cocaine injection did not cause an upregulation of DNMTs expression in the $\mathrm{NAc}$ at 1.5 hours after the last cocaine injection (Anier, Malinovskaja, Aonurm-Helm et al., 2010). These findings suggest that the different drug classes and/or duration of drug exposure may influence how drugs of abuse may affect the DNMT3a in the NAc.

Recent studies show that brain region-specific DNA methylation plays an important role in drug-related behaviors. Exposure to many drugs (cocaine, morphine, and methamphetamine) leads to DNA methylation, ${ }^{11,49-51}$ which is associated with transcriptional silencing..$^{52}$ Moreover, DNA methylation in the NAc is implicated in the regulation of cocaine-induced behavioral sensitization, ${ }^{13}$ incubation of craving, ${ }^{14}$ and reinstatement/incubation of cocaine SA. ${ }^{48}$ DNA methylation in the sperm has an impact on the heritable cocaine-seeking motivation. ${ }^{15}$ Our own studies also show that inhibition of DNMTs in the hippocampal CA1 can block the acquisition and consolidation of 
morphine/cocaine-related reward memory and that DNA methylation in the prelimbic cortex is involved in the retrieval. ${ }^{16,17}$ Additionally, we found that the reconsolidation of morphine withdrawal memory was impaired by injection of a DNMT inhibitor into the agranular insular cortex or basolateral amygdala. ${ }^{53}$ Similarly, intra-basolateral amygdala infusion of the DNMTs inhibitor 5-azacytidine hindered the reconsolidation of cocaine associated memory and then decreased subsequent reinstatement induced by cues or drug priming. ${ }^{54} \mathrm{All}$ these evidence suggests that DNA methylation in different brain regions are involved in different aspects and/or stages of drug addiction. This is also the reason that we chose to focus on the hippocampus CA1 and NAc but not other brain regions in the present study because they are involved in operant learning.

In this study, we found hippocampal DNMT3a, but not DNMT3b, played an important role in the acquisition of morphine SA. We microinjected DNMT inhibitor 5-aza or RG108 into the CA1 and found that the acquisition of morphine SA was significantly suppressed (Figures 4 and S2 and S3). These results are consistent with our previous finding showing that 5-aza injected into the CA1 impaired the acquisition of cocaine-induced and morphine-induced CPP. ${ }^{16,17}$ We also found that DNMT3a but not DNMT3b was upregulated during the morphine SA, suggesting that DNMT3a but not DNMT3b is crucial in the acquisition of morphine SA. Because 5-aza is a nonspecific inhibitor to DNMTs, we thus used AAV-DNMT3a to confirm the role of DNMT3a. Once again, knocking down DNMT3a in the CA1 was sufficient to inhibit the acquisition of morphine SA. This result suggests that DNMT3a is required for the acquisition of morphine SA via mediating DNA methylation. The DNMT3a gene codes for two isoforms, DNMT3a1 and DNMT3a2. ${ }^{55}$ Recent studies showed that expression of DNMT3a2 but not that of DNMT3a1 is regulated by neuronal activity in the hippocampus and that DNMT3a2 is required for the formation and extinction of fear memory. ${ }^{56,57}$ On the other side, DNMT3a2 but not DNMT3a1 in the NAc shell is required for cue-induced reinstatement and incubation of cocaine seeking. ${ }^{48}$ Based on these studies, we propose that DNMT3a2 but not DNMT3a1 may be required in the acquisition of morphine SA. Because neither the anti-DNMT3a antibody (Abcam, ab188470) nor the shRNA of AAV-DNMT3a used in the present study could distinguish between the DNMT3a1 and 
DNMT3a2 isoforms, a series of experiments will be needed in the future. It is worth noting that the role of DNMT3a or DNMT3b in the regulation of addictive behavior or drug memory is still controversial. LaPlant et al ${ }^{11}$ found an up-regulation of DNMT3a gene expression at 4 hours and a downregulation at 24 hours after repeated cocaine administration, while DNMT3b expression did not change significantly. ${ }^{11}$ However, Pol Bodetto et al ${ }^{58}$ reported that the DNMT3a expression and DNMT3b expression in rat CPu and PFCx were significantly upregulated at different time points after chronic cocaine treatment. ${ }^{58}$

Because we have not tested the expression of DNMT1, which is known to be involved in the maintenance of DNMTs, ${ }^{59}$ we cannot exclude the possible role of DNMT1 in the acquisition of morphine SA. Previous studies suggest that drug SA may not affect the expression of DNMT1, at least in the NAc. LaPlant et al ${ }^{11}$ reported that acute cocaine significantly reduced the expression of DNMT1; however, Dnmt1 transcripts in the NAc were not significantly altered by chronic cocaine or cocaine SA. ${ }^{11}$ Similarly, Wright et al ${ }^{49}$ found that cocaine SA up-regulated the expression of Dnmt3a and Dnmt3b, but not DNMT1, in the NAc. ${ }^{49}$ Future research needs to address whether the expression of DNMT1 in the CA1 is altered after drug SA.

Taken together, the present study demonstrates that DNMT3a in the CA1 region of the hippocampus play a key role in the acquisition of morphine-specific operant conditioning. Therefore, targeting the DNMT3a overexpression in the CA1 may be a viable approach for the treatment morphine addiction. One advantage of this approach is that natural food-seeking behaviors are less likely being affected, thus less likely to cause severe side effects.

Acknowledgments - This work was supported by Ministry of Science and Technology (2015CB553501 to NS), National Natural Science Foundation of China (31871111 and 31400880 to JJZ and 91332115 to NS), and Key Laboratory of Mental Health, Institute of Psychology, CAS. The authors declare no competing financial interests.

Authors contribution - JJZ and NS were responsible for the study concept and design. JJZ, FZJ, WZ, YD, and SBJ contributed to the acquisition of animal data. JJZ and FZJ assisted with data analysis and interpretation of findings. JJZ and FZJ drafted the manuscript. FS, JL, ML, and NS provided critical revision of the manuscript for important intellectual content. All authors critically reviewed content and approved the final version for publication. 
Funding information - Key Laboratory of Mental Health, Institute of Psychology, CAS; National Natural Science Foundation of China, Grant/Award Numbers: 31400880, 31871111 and 91332115; Ministry of Science and Technology, Grant/ Award Number: 2015CB553501

Supplemental Information follows the References at the end of the article.

\section{References}

1. Volkow N, Benveniste $H$, McLellan AT. Use and misuse of opioids in chronic pain. Annu Rev Med. 2018;69(1):451-465.

2. Das RK, Hindocha C, Freeman TP, Lazzarino Al, Curran HV, Kamboj SK. Assessing the translational feasibility of pharmacological drug memory reconsolidation blockade with memantine in quitting smokers. Psychopharmacology (Berl). 2015;232(18):3363-3374.

3. Everitt BJ, Dickinson A, Robbins TW. The neuropsychological basis of addictive behaviour. Brain Res Brain Res Rev. 2001;36(2-3):129-138.

4. Kelley $A E$, Berridge $K C$. The neuroscience of natural rewards: relevance to addictive drugs. J Neurosci. 2002;22(9):3306-3311.

5. Volkow ND, Wise RA. How can drug addiction help us understand obesity? Nat Neurosci. 2005;8(5):555-560.

6. Torregrossa MM, Taylor JR. Learning to forget: manipulating extinction and reconsolidation processes to treat addiction. Psychopharmacology (Berl). 2013;226(4):659-672.

7. Retailleau A, Morris G. Spatial rule learning and corresponding CA1 place cell reorientation depend on local dopamine release. Curr Biol. 2018;28(836-846):e834.

8. Stramiello M, Wagner JJ. Cocaine enhancement of long-term potentiation in the CA1 region of rat hippocampus: lamina-specific mechanisms of action. Synapse. 2010;64(8):644-648.

9. Wong CC, Mill J, Fernandes C. Drugs and addiction: an introduction to epigenetics. Addiction. 2011;106(3):480-489.

10. Feng J, Zhou Y, Campbell SL, et al. Dnmt1 and DNMT3a maintain DNA methylation and regulate synaptic function in adult forebrain neurons. Nat Neurosci. 2010;13(4):423-430.

11. LaPlant $Q$, Vialou V, Covington HE 3rd, et al. DNMT3a regulates emotional behavior and spine plasticity in the nucleus accumbens. Nat Neurosci. 2010;13(9):1137-1143.

12. Kinney SR, Pradhan S. Regulation of expression and activity of DNA (cytosine-5) methyltransferases in mammalian cells. Prog Mol Biol Transl Sci. 2011;101:311-333.

13. Anier K, Malinovskaja K, Aonurm-Helm A, Zharkovsky A, Kalda A. DNA 
methylation regulates cocaine-induced behavioral sensitization in mice. Neuropsychopharmacology. 2010;35(12):2450-2461.

14. Massart R, Barnea R, Dikshtein Y, et al. Role of DNA methylation in the nucleus accumbens in incubation of cocaine craving. J Neurosci. 2015;35(21):8042-8058.

15. Le $Q$, Yan $B, Y u X$, et al. Drug-seeking motivation level in male rats determines offspring susceptibility or resistance to cocaine-seeking behaviour. Nat Commun. 2017;8:15527.

16. Han J, Li Y, Wang D, Wei C, Yang $X$, Sui N. Effect of 5-aza-2- deoxycytidine microinjecting into hippocampus and prelimbic cortex on acquisition and retrieval of cocaine-induced place preference in C57BL/6 mice. Eur J Pharmacol. 2010;642(1-3):93-98.

17. Zhang JJ, Han J, Sui N. Okadaic acid blocks the effects of 5-aza-2deoxycytidine on consolidation, acquisition and retrieval of morphine-induced place preference in rats. Neuropharmacology. 2014;86:282-293.

18. Robinson TE, Kolb B. Structural plasticity associated with exposure to drugs of abuse. Neuropharmacology. 2004;47:33-46.

19. Chartoff EH, Pliakas AM, Carlezon WA Jr. Microinjection of the L-type calcium channel antagonist diltiazem into the ventral nucleus accumbens shell facilitates cocaine-induced conditioned place preferences. Biol Psychiatry. 2006;59(12):1236-1239.

20. Di Chiara G, Bassareo V, Fenu S, et al. Dopamine and drug addiction: the nucleus accumbens shell connection. Neuropharmacology. 2004;47:227-241.

21. Sutton MA, Schmidt EF, Choi KH, et al. Extinction-induced upregulation in AMPA receptors reduces cocaine-seeking behaviour. Nature. 2003;421(6918):70-75.

22. Day JJ, Childs D, Guzman-Karlsson MC, et al. DNA methylation regulates associative reward learning. Nat Neurosci. 2013;16(10): 1445-1452.

23. Roitman MF, Wheeler RA, Carelli RM. Nucleus accumben neurons are innately tuned for rewarding and aversive taste stimuli, encode their predictors, and are linked to motor output. Neuron. 2005;45(4): 587-597.

24. Assar N, Mahmoudi D, Farhoudian A, Farhadi MH, Fatahi Z, Haghparast A. D1- and D2-like dopamine receptors in the CA1 region of the hippocampus are involved in the acquisition and reinstatement of morphine-induced conditioned place preference. Behav Brain Res. 2016;312:394-404.

25. Miguens M, Kastanauskaite A, Coria SM, et al. The effects of cocaine selfadministration on dendritic spine density in the rat hippocampus are dependent on genetic background. Cereb Cortex. 2015;25(1):56-65.

26. Chen ZG, Liu X, Wang W, et al. Dissociative role for dorsal hippocampus in mediating heroin self-administration and relapse through CDK5 and RhoB signaling revealed by proteomic analysis. Addict Biol. 2017;22(6):1731-1742.

27. Fattore L, Vigano D, Fadda P, Rubino T, Fratta W, Parolaro D. Bidirectional regulation of mu-opioid and $\mathrm{CB} 1$-cannabinoid receptor in rats selfadministering heroin or WIN 55,212-2. Eur J Neurosci. 2007;25(7):2191-2200. 
28. Uchida S, Shumyatsky GP. Synaptically localized transcriptional regulators in memory formation. Neuroscience. 2017;370:4-13.

29. Burger C, Gorbatyuk OS, Velardo MJ, et al. Recombinant AAV viral vectors pseudotyped with viral capsids from serotypes 1,2, and 5 display differential efficiency and cell tropism after delivery to different regions of the central nervous system. Mol Ther. 2004;10(2): 302-317.

30. Jeon $\mathrm{M}-\mathrm{T}$, Nam JH, Shin $\mathrm{W}-\mathrm{H}$, et al. In vivo AAV1 transduction with hRheb(S16H) protects hippocampal neurons by BDNF production. Mol Ther. 2015;23(3):445-455.

31. Klugmann M, Wymond Symes $C$, Leichtlein CB, et al. AAV-mediated hippocampal expression of short and long Homer 1 proteins differentially affect cognition and seizure activity in adult rats. Molecular and Cellular Neuroscience. 2005;28(2):347-360.

32. Di Ciano P, Everitt BJ. Conditioned reinforcing properties of stimuli paired with self-administered cocaine, heroin or sucrose: implications for the persistence of addictive behaviour. Neuropharmacology. 2004;47:202-213.

33. Baunez C, Dias C, Cador M, Amalric M. The subthalamic nucleus exerts opposite control on cocaine and 'natural' rewards. Nat Neurosci. 2005;8(4):484-489.

34. Liu HS, Chefer $\mathrm{S}$, Lu H, et al. Dorsolateral caudate nucleus differentiates cocaine from natural reward-associated contextual cues. Proc Natl Acad Sci U S a. 2013;110(10):4093-4098.

35. Cameron CM, Wightman RM, Carelli RM. Dynamics of rapid dopamine release in the nucleus accumbens during goal-directed behaviors for cocaine versus natural rewards. Neuropharmacology. 2014;86: 319-328.

36. Carelli RM, Wondolowski J. Selective encoding of cocaine versus natural rewards by nucleus accumbens neurons is not related to chronic drug exposure. J Neurosci. 2003;23(35):11214-11223.

37. Yonghui L, Xigeng Z, Yunjing B, Xiaoyan Y, Nan S. Opposite effects of MK-801 on the expression of food and morphine-induced conditioned place preference in rats. J Psychopharmacol. 2006;20(1):40-46.

38. Chen $M$, Zhao $Y$, Yang $H$, et al. Morphine disinhibits glutamatergic input to VTA dopamine neurons and promotes dopamine neuron excitation. Elife. 2015;4:e09275.

39. Miller CA, Gavin CF, White JA, et al. Cortical DNA methylation maintains remote memory. Nat Neurosci. 2010;13(6):664-666.

40. Halder R, Hennion M, Vidal RO, et al. DNA methylation changes in plasticity genes accompany the formation and maintenance of memory. Nat Neurosci. 2015;19(1):102-110.

41. Egervari G, Landry J, Callens J, et al. Striatal H3K27 acetylation linked to glutamatergic gene dysregulation in human heroin abusers holds promise as therapeutic target. Biol Psychiatry. 2017;81(7):585-594.

42. Heimer L, de Olmos J, Alheid GF, Zaborszky L. "perestroika" in the basal forebrain: opening the border between neurology and psychiatry. Prog Brain 
Res. 1991a;87:109-165.

43. Heimer L, Zahm DS, Churchill L, Kalivas PW, Wohltmann C. Specificity in the projection patterns of accumbal core and shell in the rat. Neuroscience. 1991b;41(1):89-125.

44. Zahm DS, Brog JS. On the significance of subterritories in the "accumbens" part of the rat ventral striatum. Neuroscience. 1992;50(4): 751-767.

45. Di Chiara G. Nucleus accumbens shell and core dopamine: differential role in behavior and addiction. Behav Brain Res. 2002;137(1-2):75-114.

46. Jacobs EH, Smit AB, de Vries TJ, Schoffelmeer AN. Long-term gene expression in the nucleus accumbens following heroin administration is subregionspecific and depends on the nature of drug administration. Addict Biol. 2005;10(1):91-100.

47. Britt JP, Benaliouad F, McDevitt RA, Stuber GD, Wise RA, Bonci A. Synaptic and behavioral profile of multiple glutamatergic inputs to the nucleus accumbens. Neuron. 2012;76(4):790-803.

48. Cannella N, Oliveira A, Hemstedt TJ, et al. DNMT3a2 in the nucleus accumbens shell is required for reinstatement of cocaine seeking. J Neurosci. 2018;38(34):7516-7528.

49. Wright $\mathrm{KN}$, Hollis F, Duclot $F$, et al. Methyl supplementation attenuates cocaine-seeking behaviors and cocaine-induced c-Fos activation in a DNA methylation-dependent manner. J Neurosci. 2015;35(23):8948-8958.

50. Barrow TM, Byun HM, Li X, et al. The effect of morphine upon DNA methylation in ten regions of the rat brain. Epigenetics. 2017;12(12):1038-1047.

51. Cheng M-C, Hsu S-H, Chen $\mathrm{C}-\mathrm{H}$. Chronic methamphetamine treatment reduces the expression of synaptic plasticity genes and changes their DNA methylation status in the mouse brain. Brain Res. 2015;1629:126-134.

52. Nestler EJ. Epigenetic mechanisms of drug addiction. Neuropharmacology. 2014;76 Pt B:259-268.

53. Liu P, Zhang J, Li M, Sui N. Distinctive roles of 5-aza-2'-deoxycytidine in anterior agranular insular and basolateral amygdala in reconsolidation of aversive memory associated with morphine in rats. Frontiers in Behavioral Neuroscience. 2016;10:50.

54. Shi HS, Luo YX, Yin X, et al. Reconsolidation of a cocaine associated memory requires DNA methyltransferase activity in the basolateral amygdala. Sci Rep. 2015;5(1):13327.

55. Chen T, Ueda Y, Xie S, Li E. A novel DNMT3a isoform produced from an alternative promoter localizes to euchromatin and its expression correlates with active de novo methylation. J Biol Chem. 2002;277(41):38746-38754.

56. Oliveira AM, Hemstedt TJ, Bading $\mathrm{H}$. Rescue of aging-associated decline in DNMT3a2 expression restores cognitive abilities. Nat Neurosci. 2012;15(8):1111-1113.

57. Oliveira AM, Hemstedt TJ, Freitag HE, Bading H. DNMT3a2: a hub for enhancing cognitive functions. Mol Psychiatry. 2016;21(8):1130-1136. 
58. Pol Bodetto S, Carouge D, Fonteneau M, Dietrich J-B, Zwiller J, Anglard P. Cocaine represses protein phosphatase-1Cbeta through DNA methylation and methyl-CpG binding Protein-2 recruitment in adult rat brain.

Neuropharmacology. 2013;73:31-40.

59. Day JJ, Sweatt JD. Cognitive neuroepigenetics: a role for epigenetic mechanisms in learning and memory. Neurobiol Learn Mem. 2011;96(1):2-12.

Supplemental information follows

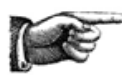




\section{Supplemental information:}

\section{Supplemental Experimental Procedures}

\section{Animals}

Eight or nine weeks old male Sprague-Dawley (SD) rats (Charles River, Beijing, China) were used: 37 rats entered the SA training, 2 were excluded due to vein catheter blockade and 6 did not acquire saccharin SA; therefore 29 rats were considered for final data analysis. The experimental procedures were carried out according to the guideline provided by the Regulation for the Administration of Affairs Concerning Experimental Animals (China, 1988). The experimental protocol was approved by Research Ethics Review Board of Institute of Psychology, Chinese Academy of Sciences.

\section{Microinjection of RG108}

The DNA methyltransferase inhibitor N-Phthalyl-L-Tryptophan (RG108, Sigma, St. Louis, MO, USA) was dissolved in 100\% DMSO to a $2 \mu \mathrm{g} / \mu \mathrm{l}$ stock solution and then diluted $1: 1$ in $0.9 \%$ sterile saline to a final $1 \mu \mathrm{g} / \mu \mathrm{l}$ solution. Rats received bilateral microinjection of RG108 (500 ng/side, $0.5 \mu \mathrm{l}$ ) to the hippocampal CA1 immediately before each morphine SA daily test session (Maddox, Watts \& Schafe, 2014). The vehicle group received isovolumetric 50\% DMSO in 0.9\% sterile saline injection. Hamilton microsyringe $(10 \mu \mathrm{l})$ and a syringe pump (RWD Life Science, Shenzhen, China) were used to deliver RG108 or vehicle. The injection rate was $0.25 \mu \mathrm{l} / \mathrm{min}$ over $2 \mathrm{~min}$ and then the injection needle remained in the guide cannula for another 2 min to prevent backflow. After injection, stainless plugs were put back into the guide cannula.

\section{Statistical analysis}

We used two-way analysis of variance (ANOVA) to analyze the behavioral data and the Western blot data. The analysis of the nosepokes data included the between-subjects factor of nose-poke 
(active, inactive) and the within-subjects factor of training day (7 levels). The analysis of the \%NPa data included the between-subjects factor of treatment (RG108, Vehicle) and within-subjects factor of training day (7 levels). The analysis of the DNMTs expression data included the between-subjects factor of treatment (naive, SA saccharin) and within-subjects factor of training day (1 Day, 7 Day). Bonferroni post hoc analysis was performed after two-way ANOVA if necessary. Statistical significance was set at $P<0.05$. Data are expressed as mean \pm SEM and all statistical analyses were performed using GraphPad Prism version 6.00 for Windows.

\section{Other methods}

Please see the "MATERIALS AND METHODS" part.

\section{Supplemental Experimental results}

A

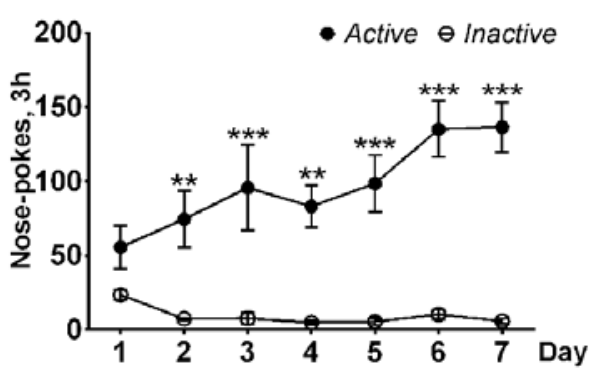

B

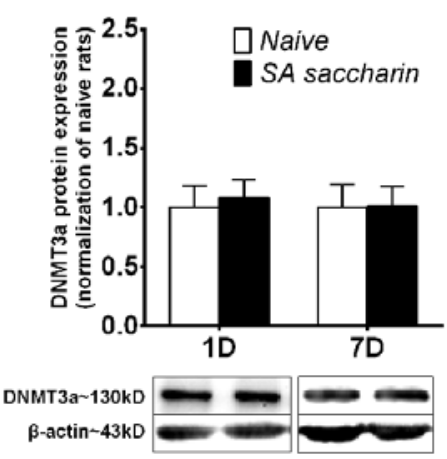

C

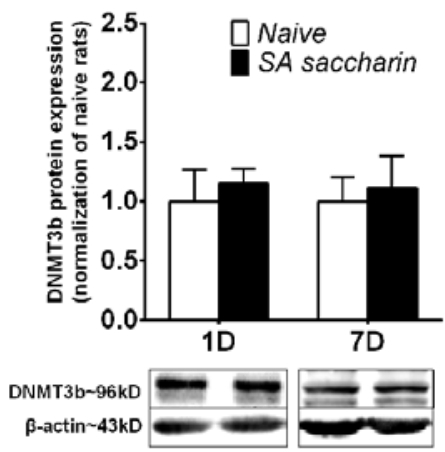

Figure S1. Three hours saccharin SA had no significant effect on the expression of DNMT3 in the CA1. (A). Rats received 3 hours saccharin SA daily for 7 days and acquired saccharin SA (nose-poke factor: $F_{1,82}=140.6, P<0.001$; nose-poke $\times$ training day interaction: $F_{6,82}=3.86, P<0.01$; training day factor: $F_{6,82}=2.08, P=0.06$, $n=6-12)$. Post hoc comparisons revealed that rats poked the active hole significantly more than the inactive hole since the second day of training $(P<0.01)$. (B). Three hours saccharin SA training did not affect the expression of DNMT3a in the CA1 (treatment factor: $F_{1,19}=0.07, P=0.79$; treatment $\times$ training day interaction: $F_{1,19}=0.04, P=0.84$; training day factor: $\left.F_{1,19}=0.04, P=0.84 ; n=5-6\right)$. (C). Three hours saccharin SA training did not affect the expression of DNMT3b in the CA1 (treatment factor: $F_{1,18}=0.33, P=0.57$; treatment $\times$ training day interaction: $F_{1,18}=$ $0.01, P=0.94 ;$ training day factor: $\mathrm{F}_{1,18}=0.01, P=0.94 ; \mathrm{n}=5-6$ ). 


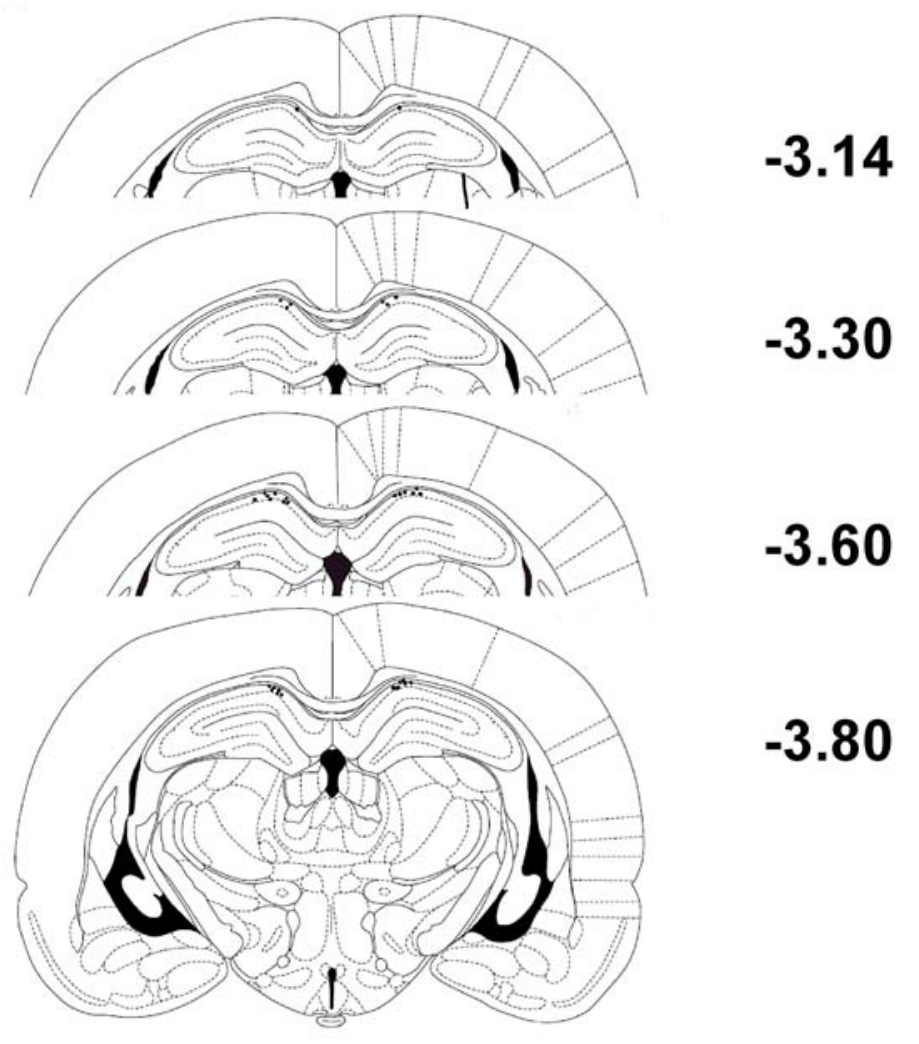

Figure S2. Schematic representations of the RG108 intracranial cannula infusion sites in the hippocampal CA1. Numbers besides the sections indicate anteroposterior distance from bregma in millimeters. Data are reconstructed from Paxinos and Watson (2007). 
Figure S3.

Microinjection of RG108 into the CA1 inhibited the acquisition of morphine SA. (A). For the vehicle group, two-way repeated measures ANOVA revealed significant main effects of nose-poke $\left(F_{1,16}=84.48, P<\right.$ $0.001)$, training day factor $\left(\mathrm{F}_{6,96}=2.50\right.$, $P<0.05)$ and nosepoke $\times$ training day interaction $\left(\mathrm{F}_{6,96}=\right.$ $7.27, P<0.001)$. Post hoc comparisons revealed that there were more active nose-pokes than inactive nose-pokes since the second day $(P<0.01)$. (B). Microinjection of RG108 into the CA1 inhibited the acquisition of morphine SA (nosepoke: $F_{1,16}=8.31$, $P<0.05$; nosepoke $\times$ training day interaction: $\mathrm{F}_{6,96}=1.55, P=$ 0.17 ; training day factor: $F_{6,96}=1.66$, $P=0.14)$. Post hoc comparisons revealed that active nose-pokes were more than inactive nose-pokes only at the $7^{\text {th }}$ training day $(P<0.01)$. (C). The \%NPa of the RG108 group was less than the \%NPa of the vehicle group (treatment factor: $\mathrm{F}_{1,16}=17.35, P<0.001$; treatment $\times$ training day interaction: $\mathrm{F}_{6,96}=1.46, P=0.20$; training day factor: $\mathrm{F}_{6,}$ $\left.{ }_{96}=7.80, P<0.001\right)$. Therefore, microinjection of RG108 into the CA1 inhibited the acquisition of morphine SA. Data are presented as mean \pm SEM., $\mathrm{n}=9$, ${ }^{* *} P<$

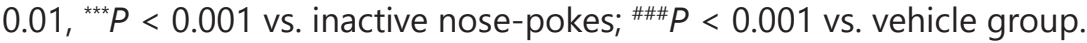

A

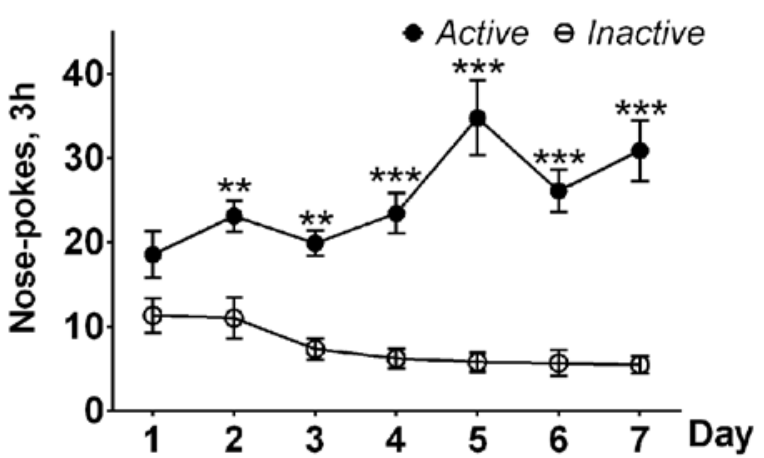

B

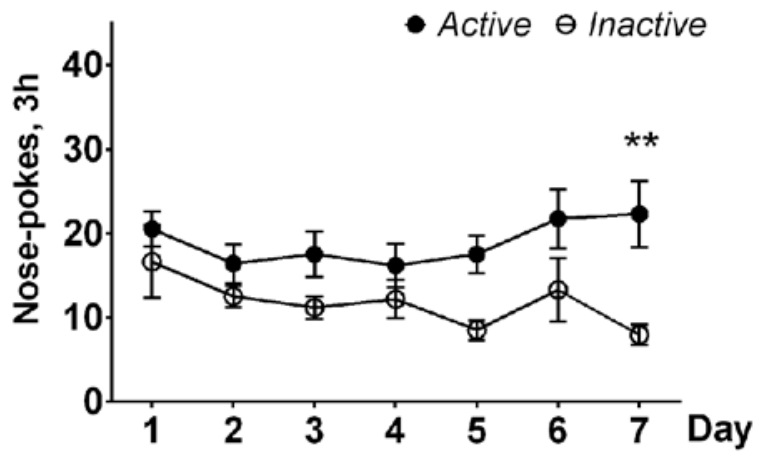

C

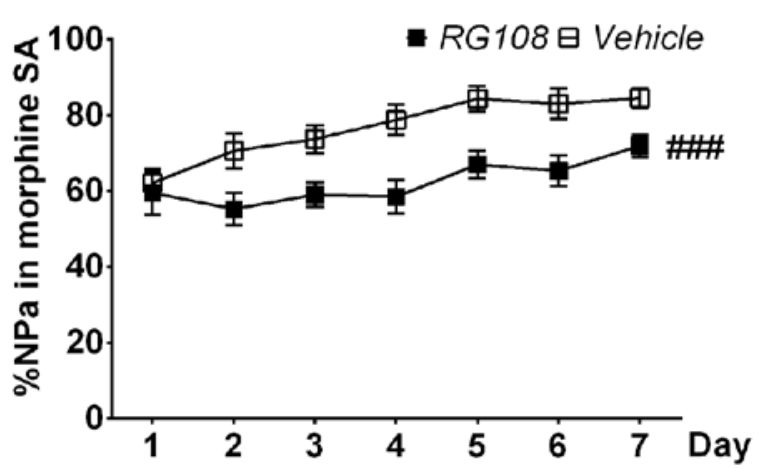

